\title{
Investigating Students' Emotional Stability as a Predictor of Stress Management while Engaging in Flexible Online Learning during COVID-19
}

Irene V. Manlunas ${ }^{1}$, Bernel V. Carredo ${ }^{1}$, Edith Abigail C. Daan ${ }^{1}$, Juliano B. Enriquez ${ }^{1}$, Mary Judail Fernan $^{1}$, Emilio Jose P. Tayurang ${ }^{1}$, Flordeliza S. Gagani ${ }^{1}$

fsgagani@usc.edu.ph

${ }^{1}$ University of San Carlos Basic Education Department Senior High South School, Cebu City Philippines

\begin{abstract}
Due to the COVID-19 pandemic, restrictions and guidelines are being enacted for the safety of the people, and generally, it has caused difficulties in the daily activities among students. Hence, this quantitative non-experimental study aimed to determine if emotional stability is a predictor of stress management among Senior High School students of the University of San Carlos in Cebu City, Philippines in the school year 2020-2021, who engage in a flexible online modality of learning. Adapted Likert-type survey tools were utilized to gather data online from 80 Grade 12 students who were selected through stratified non-proportionate random sampling. Results using linear regression analysis revealed a significant R and R2 value of .28 and .08 (adjusted R2 was .07) respectively, which means highly significant $F(1,78)=6.79$, MS residual $=.31, \mathrm{p}<.05$ using a $95 \%$ level of confidence with a .39 standard error of the estimate from the population standard deviation of the residuals. This means that the independent variable emotional stability (ES) significantly and statistically affects the dependent variable stress management $(\mathrm{SM})$. The modeled equation $\mathrm{SM}=1.71+.50(\mathrm{ES})$ predicts that the higher the level of emotional stability, the higher the level of stress management. This implies that emotionally stable students are better at managing their stress. These results encouraged collaboration among the academic and administrative support services in every institution and stronger social support at home. This time, parental involvement plays a vital role in the holistic development and formation of every student.
\end{abstract}

Keywords: Flexible Class, Hybrid Learning, Learning Modalities, Linear Regression

Received: April 9, 2021

Revised: May 17, 2021

Accepted: June 29, 2021

\section{Introduction}

The restrictions imposed due to the COVID-19 pandemic have created difficulties and hardships in the daily lives of people, particularly students. One of the important fundamentals in health that should be taken into account is the mental well-being of these students. These play a vital role in instituting coping mechanisms that help in the time of stress, particularly in the present, where students are faced with the pandemic that has changed their way of doing their daily tasks.

Generally, stress is something that cannot be avoided, and therefore, students must learn the strategies of coping. A study conducted by Seňová and Antošová (2014) has proven that stress can affect people in every field, leading to accumulated difficulties, particularly in countries like Slovakia, with similar conditions in Australia (Pascoe, Hetrick, \& Parker, 2020) and India (Mahapatra \& Sharma, 2020). Stress in the academic context challenges the students with their ways of dealing with and handling it daily. In the Philippines, students' situations vary from each other, which provides stress such as personal factors, financial difficulties, lower grades, 
and balancing of work and study. In addition, other common causes of stress are school requirements, projects, writing research or thesis (Mazo, 2015), academic challenges, and subject workloads, as well as balancing the time between personal, academic, and extracurricular tasks (Dy, Espiritu-Santo, Ferido, \& Sanchez, 2015). Stress is undoubtedly the top-reported obstacle to overall performance, as learners are reported to be experiencing more stress than before (Hemamalini, Ashok, \& Sasikala, 2018). It must be addressed now, especially in this pandemic, where the burden of online education and the academic and curricular demands of today, particularly in strands where it is matter-intensive and the technical approach to the subject is high.

However, stress management helps the body and mind to adapt resiliency, ranges the tools to reset one's alarm and reactive system and feels the relaxation the body needs (Mayo Clinic, 2019). Stress management techniques, as well as stress reduction techniques, further the life quality of the students by lowering the levels of stress which, in turn, fewer indicators of disease symptoms (Sternberg, 2009). According to the study of Tuncay, Müdüroglu, and Bulut (2020), more than half of the students garnered stress from education. Interventions are required to assist learners with stress management techniques applied in various stages of education.

On the other hand, the concept of emotional stability is the ability to keep one's emotional balance under pressure. Smitson (1974) defines emotional stability as the process of the personality constantly aiming for better internal and external emotional health. They can tolerate minor stresses, lows, and strains daily without becoming emotionally upset, anxious, nervous, tense, or angry. Thus, children should control and express their emotions in an appropriate manner. Scott (1968) stated that emotional stability is nevertheless important in having superior mental health and if a student has very little to no emotional control, this could lead to the development of negative psychological reactions.

Furthermore, Zapata (2015) stated that calm students are individuals, which are not faced with high-running and extreme emotions and passions. Instead, they display tranquility and present a stress-free disposition. Serebryakova et al. (2016) stated that emotional stability is a prime factor in developing management skills in different fields for students in higher education. These emotions, if controlled, can prove to be a useful asset in a person's development (Pandey, 2017), and it is important to take note of the variable into account. In their dissertation, Kumar and Bhukar (2013) defined emotional stability as one's capacity to balance emotions under situations of pressure and should be taken into account.

This study is anchored on Lazarus' Theory of Psychological Stress and Freud's Psychodynamic Theory. Two concepts central to the stress theory were coined: appraisal, which entails the evaluation of one's experiences to manage their well-being; and coping, which entails one's efforts to manage pressures (Lazarus, 1993) as cited by Biggs, Brough, and Drummond (2017). Stress is seen as a link between people and their environments. The stress eliminates from the environment of the individual, in particular, the student and their school work, to be precise, showing that it is, in fact, a transaction between two parties that have implications on the stress level and management that they demonstrate (Krohne, 2002). On the other hand, Freud's Psychodynamic Theory ponders on individuals experiencing conflicting emotions and experiences towards a stimulus, as mental responses happen in an independent yet parallel method. As such, similar conflicts can lead to contradictions that require internal compromise (Vinney, 2020). The human function is based on the internal processes of the person, notably in the unconscious parts and the different personality areas (McLeod, 2019).

In correlation, adding factor to this is the fact that this change came absolutely out of nowhere suddenly, therefore not giving them the time needed to cope and adapt with the inevitable change brought upon them. This has greatly deterred the emotional state of most students as

Copyright ( 2021 , International Journal Papier Public Review, Under the license CC BY-SA 4.0 DOI: https://doi.org/10.47667/ijppr.v2i2.89 
their drive and motivation have drastically declined due to the negative variables or factors that came along with the new systemized form of learning.

These theories strengthen the connection between emotional stability and the level of stress management among Senior High school students. It is noted that since the start of the pandemic, there have been no studies being conducted yet using these variables, settings, and respondents. Figure 1 presents the conceptual framework of the study.

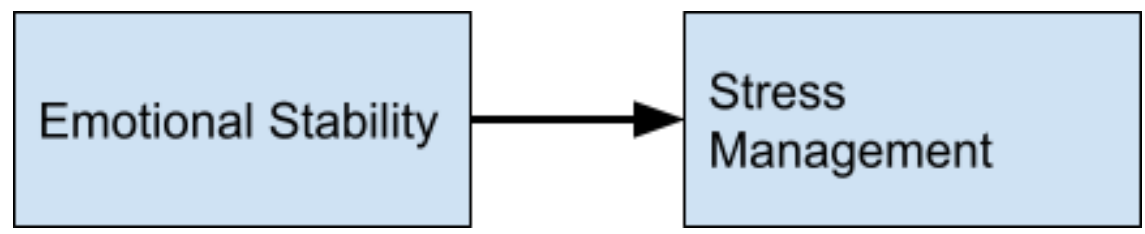

Figure 1. Conceptual Framework

Hence, the main purpose of the study is to determine if emotional stability predicts the stress management levels among Grade 12 Senior High School students at the University of San Carlos that conforms to the new normal in S.Y. 2020-2021. Specifically, this study aims to determine the level of emotional stability and stress management among Grade 12 Senior High School students and the corresponding recommendations that can be done based on the findings of the study.

The researchers hypothesized $\left(\mathrm{H}_{1}\right)$ that emotional stability significantly predicts stress management. The study is only limited to the Grade 12 Senior High School students at the University of San Carlos (USC) - South Campus in the academic track, particularly the Accounting, Business, and Management (ABM) strand, the Science, Technology, Engineering and Mathematics (STEM) strand, Humanities and Social Sciences (HUMSS) strand, and the Arts and Design (A\&D) track. The outcome of this study has a significant contribution to the students, teachers, parents, guidance counselors, administrative officials, school heads, and future researchers.

\section{Methods}

A quantitative non-experimental research design was employed in this study since the study did not undergo manipulation of variables such as having experimental and control groups. A $\mathrm{g}$ *power analysis was used to determine the sample size of 80 to achieve a .95 power. These eighty (80) respondents, as shown in Table 1, were selected using stratified non-proportionate random sampling, which was taken from the sampling frame. This frame consists of the list of all Grade 12 students enrolled in the different academic strands of the school year 2020 - 2021 in the University of San Carlos, Basic Education Department-Senior High School (USC-BED SHS). The USC, a private sectarian University and managed by the Society of the Divine Word (SVD) priests, is composed of 5 campuses situated in Cebu City, Philippines, namely, North Campus, South Campus, Downtown Campus, Montessori Campus, and Talamban Campus. The BED-Senior High which is situated in the South, North, and Talamban campus, consists of two schools - the South School, which caters to the Accountancy and Business Management (ABM), and Humanities and Social Sciences (HumSS) strands, and Arts \& Design (A\&D) track; and the North School, which handles the Science, Technology, Engineering and Mathematics (STEM) strand.

Table 1. Respondents of the study

\begin{tabular}{|c|c|c|c|c|c|}
\hline Strand & $\boldsymbol{f}$ & $\mathbf{R f}(\boldsymbol{\%})$ & Gender & $\mathbf{f}$ & $\mathbf{R f}(\boldsymbol{\%})$ \\
\hline ABM & 60 & $76.74 \%$ & Female & 47 & $66.70 \%$ \\
\hline STEM & 17 & $17.60 \%$ & Male & 33 & $33.30 \%$ \\
\hline
\end{tabular}




\begin{tabular}{|c|c|c|l|l|l|}
\hline $\mathrm{AD}$ & 3 & $5.66 \%$ & & & \\
\hline TOTAL & $\mathbf{8 0}$ & $\mathbf{1 0 0 . 0 0 \%}$ & & & \\
\hline
\end{tabular}

In any research study, the survey instrument plays a crucial role in the process of arriving at reliable and valid results. Sorono-Gagani and Bonotan (2017) compared any research instrument as the captain of the ship as this controls everything since an invalid tool produces invalid and inaccurate results. In this study, two adapted 4-point Likert-type survey questionnaires from strongly disagree (1) to strongly agree (4) were utilized to gather the data online. Likert-type is an ordinal variable that was converted into an interval continuous variable for the Pearson $r$ to fit in. The tool went through the face and content validation through hiring research experts including the research adviser and the panelist, to check if the items measure what they are supposed to measure. In terms of the internal consistency of the items, pilot testing was done and obtained reliability coefficients of .87 for stress management and .72 for emotional stability, which were considered good and acceptable according to George and Mallery (2003) as cited by Blanco et al. (2020).

After having validated the tool, letters of approval for the conduct of the final data collection were obtained from the school administration. Informed consent was obtained from the respondent, and proper orientation was done regarding the objectives and procedures and the confidentiality of data. All respondents were assured that all data must be kept confidential and for educational purposes only. In the process of gathering, all respondents were reminded of their freedom to participate or withdraw anytime. The questionnaires were administered via Google Forms and distributed through Messenger. Respondents were given a week to answer the survey tool before retrieving it from them. In analyzing and interpreting the gathered data, the researchers used accessible technology applications such as Microsoft Excel and Microsoft Word to organize the procedure and results of the study.

To analyze the data gathered, descriptive statistics were utilized in determining the profile and the extent of emotional stability and stress management among the respondents. To know if the independent variable influences the dependent variable, simple linear regression analysis was used to investigate the effect of one independent variable, which was the emotional stability, on the outcome variable or the dependent variable, which was the stress management (Sullivan, 2017) among Grade 12 Senior High School students.

\section{Results and Discussion}

Based on the result, the histogram (figure 1) and the normal P-P plot of regression standardized residual (figure 2) showed no detection of substantial departures and signal no serious violations from the assumptions of normality.

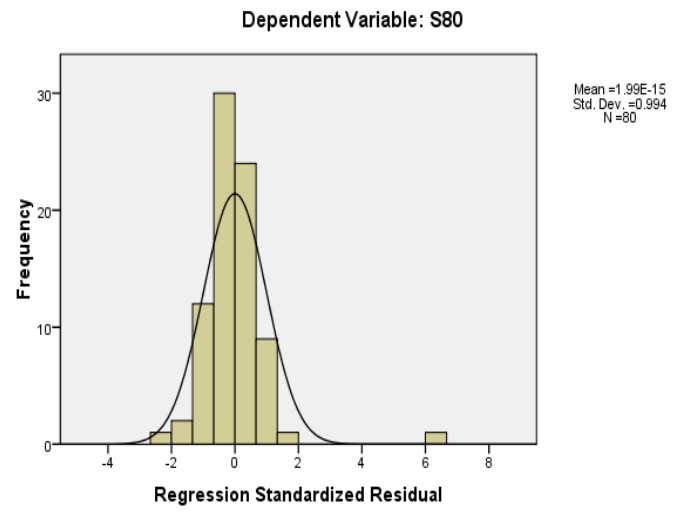

Figure 1. Histogram of stress management

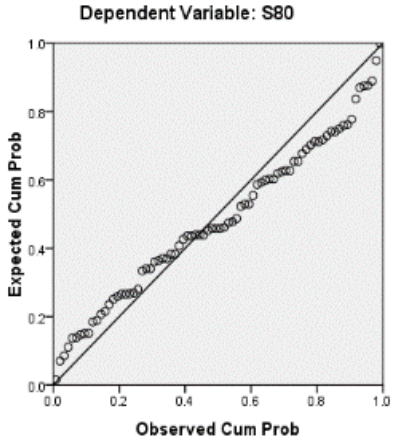

Figure 2. Normal P-P Plot of Regression 
Hence, linear regression analysis was applied to determine if emotional stability affects the stress management level of learners who engage in online learning during the pandemic. Table 2 presents the extent of emotional stability among the learners.

Table 2. Level of Emotional Stability

\begin{tabular}{|l|c|l|l|}
\hline \multicolumn{1}{|c|}{ Items } & Mean & SD & $\begin{array}{l}\text { Descriptio } \\
\text { n }\end{array}$ \\
\hline 3 I recognize how my feelings affect my performance & 3.48 & 0.61 & Very High \\
\hline $\begin{array}{l}\text { 7 I am open to candid feedback, new perspectives, continuous } \\
\text { learning, and self-development }\end{array}$ & 3.33 & 0.69 & Very High \\
\hline 6 I am reflective and try to learn from experience & 3.29 & 0.74 & Very High \\
\hline 8 I can show a sense of humor and perspective about myself & 3.25 & 0.81 & High \\
\hline 5 I am aware of my strengths and weaknesses & 3.01 & 0.87 & High \\
\hline 4 I have a guiding awareness of my values and goals & 2.98 & 0.81 & High \\
\hline 2 I realize the links between my feelings and what I think, do, and say & 2.96 & 0.77 & High \\
\hline 9 I present myself with self-assurance; I have "presence" & 2.84 & 0.71 & High \\
\hline $\begin{array}{l}\text { 10 I can voice views that are unpopular and go out on a limb for what } \\
\text { is right }\end{array}$ & 2.75 & 0.77 & High \\
\hline $\begin{array}{l}\text { 11 I am decisive and able to make sound decisions despite } \\
\text { uncertainties and pressures }\end{array}$ & 2.66 & 0.82 & High \\
\hline 1 I always know which emotions I am feeling and why & 2.60 & 0.75 & High \\
\hline \multicolumn{1}{|c|}{ Overall Mean Rating } & 3.01 & 0.76 & High \\
\hline
\end{tabular}

Interval: $1.00-1.75$ (Very Low); 1.76 - 2.50 (Low); $2.51-3.25$ (High); 3.26 - 4.00 (Very High)

Based on the table, only a few of the items were rated very high. The highest-rated item imposed the students' capability of recognizing how their emotions affect their performance as an individual and as a student, which rated very high $\left(x^{-}=3.48, \mathrm{SD}=0.61\right)$. The outcome suggests that the students do acknowledge and are aware of their emotions and how those affect their self-presentation. However, the majority of the items were rated high by the students. The lowest-rated imposed the student's knowing what emotions and feelings they are experiencing and the reason behind it, which produced a rate of high $\left(x^{-}=2.6, S D=0.75\right)$. The result would mean that the students possess an awareness for whatever emotions they experience in every situation.

Overall, table 2 obtained a result of a high level of emotional stability with a totality mean rating high $\left(x^{-}=3.01, \mathrm{SD}=0.76\right)$ among the Grade 12 Senior High School students. According to Smitson (1974) and Scott (1968), emotional stability is defined as the process of the personality constantly aiming for better internal and external emotional health and an important factor in having superior mental health. The results indicate that with the emergence of the COVID-19, in terms of emotions, students are highly aware of their feelings, thoughts, strengths, and weaknesses and have secured self-assurance within themselves. Moreover, the students are open-minded to new learnings, experiences, and perspectives that encourage selfdevelopment. The current findings have the same findings in the study of Pandey (2017) that students with psychological consistency of their emotions and moods are more likely to possess self-respect, security, and self-confidence.

Even so, several studies have found out that the development of mental health problems is higher at risk due to COVID-19 being isolated from each other (Elmer, Mepham, \& Stadtfeld, 2020). Concern, disappointment, anger, and pride are frequently experienced in an online learning community (Rha \& Sung, 2005). In addition, Son, Hegde, Smith, Wang, \& Sasangohar (2020) on the outbreak of COVID-19, 71\% of the respondents have developed increased levels 
of anxiety and stress. Fears, worries about their health and of their loved ones, difficulty in concentrating, disruptions to sleeping patterns, decreased social interactions due to physical distancing, and increased concerns on academic performance are the stressors that contributed to the students that can impede self-development. In terms of how students manage their stress, table 3 revealed a high $\left(x^{-}=2.67, S D=0.83\right)$ level of ability to manage stress among Grade 12 Senior High School students.

Table 3. Level of Stress Management

\begin{tabular}{|l|l|l|l|}
\hline \multicolumn{1}{|c|}{ Items } & $\begin{array}{l}\text { Mea } \\
\text { n }\end{array}$ & SD & $\begin{array}{l}\text { Descriptio } \\
\mathrm{n}\end{array}$ \\
\hline $\begin{array}{l}\text { 3 How much better do you feel in stabilizing/overcoming your stress } \\
\text { when doing therapeutic practices? }\end{array}$ & 3.40 & 0.85 & Very High \\
\hline 1 How would you rate the level of your stress at home? & 3.32 & 0.82 & Very High \\
\hline $\begin{array}{l}\text { 5 How often in a span of your 1 month do you undergo intense } \\
\text { emotional breakdowns? }\end{array}$ & 3.21 & 1.03 & High \\
\hline 2 How does the amount of school work give you stress level? & 3.17 & 0.64 & High \\
\hline $\begin{array}{l}\text { 6 Rate your satisfaction level in managing your emotions after seeing } \\
\text { the local guide in your school }\end{array}$ & 2.84 & 0.90 & High \\
\hline $\begin{array}{l}\text { 12 Different practices you do to manage your emotions or stabilize } \\
\text { your stress level. }\end{array}$ & 2.70 & 0.68 & High \\
\hline 4 How many attempts have you made to relieve stress? & 2.66 & 0.80 & High \\
\hline 10 How do you ensure stressful situations don't affect your work? & 2.64 & 0.73 & High \\
\hline $\begin{array}{l}\text { 11 How do you prevent situations from getting too stressful to } \\
\text { manage? }\end{array}$ & 2.63 & 0.71 & High \\
\hline $\begin{array}{l}\text { 8 Do you ever feel run down or drained of physical or emotional } \\
\text { energy? }\end{array}$ & 2.54 & 0.87 & High \\
\hline $\begin{array}{l}\text { 7 In the last month, how often have you felt confident about your } \\
\text { ability to handle your problems? }\end{array}$ & 2.01 & 0.85 & Low \\
\hline 9 Do you ever feel that you have no one to talk to? & 1.84 & 1.05 & Low \\
\hline \multicolumn{1}{|c|}{ Overall Mean Rating } & 2.67 & 0.83 & High \\
\hline
\end{tabular}

Interval: 1.00 - 1.75 (Very Low); 1.76 - 2.50 (Low); 2.51 - 3.25 (High); 3.26 - 4.00 (Very High)

The students' stress at home and their coping strategies to overcome stress are the only ones rated very high. The very high $\left(x^{-}=3.40, S D=0.85\right)$ rating indicated that students can look for strategies to cope up when they are stressed. Therefore, students feel better when they find effective coping strategies to manage stress. However, in terms of the students' feelings toward being alone got the lowest level $\left(x^{-}=1.84, S D=1.05\right)$. It means that the students are comfortable with someone they trust with their problems.

In totality, the extent of the student's ability to manage stress is high $\left(x^{-}=2.67, S D=0.83\right)$, which means that students are more likely knowledgeable in managing stress. These results are similar to the findings of Brown and Gerbarg (2012) and Cuddy (2015) that mindfulness, meditation, cognitive-behavioral strategies, and healthy living are some of the important coping strategies to manage stress. Mason (2017) also reported that even though the students go through stress, they engage in multiple coping strategies to manage challenges. The students can take control over stressful situations and practice coping and therapeutic strategies to relieve stress. The development of stress management skills has a significant impact on psychological well-being (Alborzkouh, Nabati, Zainali, Abed, \& Ghahfarokhi, 2015).

However, some studies revealed that stress affects students academically and leads them to have bad performance in schoolwork. Stress affects the productivity of the students 
(Hemamalini, Ashok, \& Sasikala, 2018). Moreover, family, personal, peer, and school problems are the four aspects of adolescents' concerns on the academic stress of students (Huan, See, Ang, \& Har, 2008). With the adaptation to the new normal, isolation, loneliness, financial instability, and changes in the work environment are some of the primary causes of stress among Filipino students and their households (de Walque, Friedman, Gatti, \& Mattoo, 2020).

On the other hand, table 4 indicated a statistically significant correlation between the two variables, $\mathrm{r}(78)=.283, \mathrm{p}=.011, \mathrm{p}<.05$ at 0.05 level (2-tailed) of significance. This means that the degree and the strength of the relationship between emotional stability and stress management are found to be weakly positive.

Table 4. Correlation

\begin{tabular}{|ll|r|r|}
\hline & & \multicolumn{1}{|c|}{$\begin{array}{c}\text { Emotional } \\
\text { Stability }\end{array}$} & $\begin{array}{c}\text { Stress } \\
\text { Management }\end{array}$ \\
\hline Emotional Stability & Pearson Correlation & 1 & $.283^{\circ}$ \\
& Sig. (2-tailed) & & .011 \\
& $\mathrm{~N}$ & 80 & 80 \\
\hline Stress Management & Pearson Correlation & $.283^{\prime}$ & 1 \\
& Sig. (2-tailed) & .011 & 80 \\
& $\mathrm{~N}$ & 80 & \\
\multicolumn{2}{|c|}{} \\
\end{tabular}

In addition, the results of linear regression for stress management as a criterion and emotional stability as its predictor variable for Grade 12 Senior High school students are presented in table 5, the model summary, which indicates that the variance $(6.80 \%)$ in stress management is being explained by emotional stability; and table 6, the ANOVA results.

Table 5. Model Summary

\begin{tabular}{|l|c|r|r|r|}
\hline Model & $\mathrm{R}$ & \multicolumn{1}{c|}{$\begin{array}{c}\mathrm{R} \\
\text { Square }\end{array}$} & $\begin{array}{r}\text { Adjusted } \\
\text { R Square }\end{array}$ & $\begin{array}{r}\text { Std. Error of } \\
\text { the Estimate }\end{array}$ \\
\hline 1 & $.283^{\mathrm{a}}$ & .080 & .068 & .55577 \\
\hline
\end{tabular}

a. Predictors: (Constant), Emotional Stability

b. Dependent Variable: Stress Management
Table 6. ANOVA Results

\begin{tabular}{l|r|r|r|r|r|}
\hline Model & $\begin{array}{r}\text { Sum of } \\
\text { Squares }\end{array}$ & $\mathrm{df}$ | & $\begin{array}{r}\text { Mean } \\
\text { Square }\end{array}$ & $\mathrm{F}$ & Sig. \\
\hline 1 Regression & 2.098 & 1 & 2.098 & 6.792 & $.011^{\mathrm{a}}$ \\
Residual & 24.093 & 78 & .309 & & \\
Total & 26.191 & 79 & & & \\
\hline
\end{tabular}
a. Predictors: (Constant), Emotional Stability
b. Dependent Variable: Stress Management

Since the study aims to determine if the independent variable influences the dependent variable, the model summary, and the ANOVA result showed a significant $\mathrm{R}$ and $\mathrm{R}^{2}$ value of .28 and .08 (adjusted $\mathrm{R}^{2}$ was .07$)$, respectively. This means that there is a highly significant $\mathrm{F}(1,78)=$ 6.79 , MSresidual $=.31, \mathrm{p}<.05$ using a $95 \%$ level of confidence with a .56 standard error of the estimate from the population standard deviation of the residuals. Moreover, table 7 presented the coefficients of the independent variable, with the $p$-value of the t-test that emotional stability $(\mathrm{ES})(\mathrm{t}(79)=2.61, \mathrm{p}<.001)$ is found to be a significant predictor of stress management among senior high school students.

Table 7. Coefficients

\begin{tabular}{|c|c|c|c|c|c|c|}
\hline & & \multicolumn{2}{|c|}{$\begin{array}{c}\text { Unstandardized } \\
\text { Coefficients }\end{array}$} & $\begin{array}{c}\text { Standardized } \\
\text { Coefficients }\end{array}$ & $\mathrm{t}$ & Sig. \\
\hline & & $\mathrm{B}$ & Std. Error & Beta & & \\
\hline 1 & (Constant) & 1.706 & 0.519 & & 3.286 & 0.002 \\
\hline & Emotional Stability & 0.503 & 0.193 & 0.283 & 2.606 & 0.011 \\
\hline
\end{tabular}

a. Dependent Variable: Stress Management 
Since there is enough evidence that emotional stability significantly predicts stress management, then the researchers' hypothesis $\left(\mathrm{H}_{1}\right)$ indicating the influence of emotional stability on stress management is accepted. Hence, the modeled equation for predicting levels of emotional stability of a person related to one's ability to manage stress was found to be: Stress Management $(S M)=1.71+.50(E S)$. The model showed all positive coefficients, which means that as the value of the independent variable increases, the mean of the dependent variable also tends to increase. The predictor ES with a positive coefficient of .50 represents the mean increase of the outcome variable (SM) for every additional one unit. This further means that if the ES increases by 1 unit, the average SM increases also by about .50 .

These results imply that the emotional upbringing of senior high students would likely predict the way they handle the stress and burdens of various demands. The emotional upbringing of students includes the feeling of satisfaction, self-assurance, and internal reflectiveness as students continue to accomplish their academic and personal priorities. This confirms the statements presented by Zapata (2015) and Serebryakova et al. (2016) that emotional stability is a prime factor that is essential in developing management skills, one of which is stress management that helps in discerning a stress-free disposition in a student.

These new results supported Lazarus' theory that the person can cope with their burdens, along with Freud's theory that emotional triggers can bring a large influence on the internal processes in the body. These findings further indicated that no matter how perfect the school environment is, having the latest and the most advanced facilities, technologies, instructional materials, and having supportive school heads, it is with the students' emotional upbringing that affects their ways of coping and handling of with stress caused by the academic pressures and personal woes. However, since this study had only limited samples and variables, then further studies may validate the researchers' findings since different factors can affect emotional stability due to the current educational system.

\section{Conclusion}

Based on the results, there was enough evidence that emotional stability is a predictor of stress management among Senior High School students who engage in a flexible learning modality in this time of the pandemic. Being emotionally stable contributes towards better management of stress among these students. The way the student controls and manages his emotions influences the way he manages stress from academic pressures and personal thoughts. These results implied that the better the students are in managing their emotions and stabilizing them, the better they are in managing their stress caused by external factors. These also imply that students with high levels of stress management and emotional stability can manage stress and have stable emotions, whereas students with low levels of stress management and emotional stability struggle to handle stress caused by internal and external factors. Hence, the researchers highly recommend teachers, students, administrators, and the entire academic community be more understanding and considerate with the students, particularly in the incumbent online setting. Parental and social support from the home environment is also needed since emotional upbringing and control of students may start at home. These social supports play a significant role in predicting the way these students handle stress and pressures brought by the new learning modality caused by the COVID-19 pandemic.

\section{References}

Alborzkouh, P., Nabati, M., Zainali, M., Abed, Y., \& Ghahfarokhi, F. S. (2015). A review of the effectiveness of stress management skills training on academic vitality and psychological well-being of college students. Journal of medicine and life, 8 (Spec Iss 4), 39. 
Biggs, A., Brough, P., \& Drummond, S. (2017). Lazarus and Folkman's psychological stress and coping theory. The handbook of stress and health: A guide to research and practice, 351-364.

Blanco, Q. A., Carlota, M. L., Nasibog, A. J., Rodriguez, B., Saldaña, X. V., Vasquez, E. C., \& Gagani, F. (2020). Probing on the Relationship between Students' Self-Confidence and Self-Efficacy while engaging in Online Learning amidst COVID-19. Journal La Edusci, 1(4), 16-25.

Brown, R., \& Gerbarg, P. (2012). The healing power of the breath: Simple techniques to reduce stress and anxiety, enhance concentration, and balance your emotions. Shambhala Publications.

Cuddy, A. (2015). Presence: Bringing your boldest self to your biggest challenges. Hachette UK.

de Walque, D., Friedman, J., Gatti, R., \& Mattoo, A. (2020). How two tests can help contain COVID-19 and revive the economy.

Dy, M., Espiritu-Santo, K., Ferido, M., \& Sanchez, R. (2015). Stressors and stress responses of Filipino college students. Asia life sciences, 24(2), 737-759.

Elmer, T., Mepham, K., \& Stadtfeld, C. (2020). Students under lockdown: Comparisons of students' social networks and mental health before and during the COVID-19 crisis in Switzerland. Plos one, 15(7), e0236337.

George, D., \& Mallery, P. (2003). SPSS for Windows Step-by-Step: A Simple Guide and Reference, 14.0 update (7th Edition). Retrieved from: http://lst-iiep.iiepunesco.org/cgi-bin/wwwi32.exe/[in=epidoc1.in]/?t2000=026564/(100).

Hemamalini, R., Ashok, V., \& Sasikala, V. (2018). A Study on Stress Management and its Impact among Students. International Journal of Academic Research in Economics and Management Sciences, 7(3), 101-110.

Huan, V. S., See, Y. L., Ang, R. P., \& Har, C. W. (2008). The impact of adolescent concerns on their academic stress. Educational Review, 60(2), 169-178.

Larsson, G. (2010). The Emotional Stress Reaction Questionnaire (ESRQ): Measurement of Stress Reaction Level in Field Conditions in 60 Seconds.

Lazarus, R. S. (1993). From psychological stress to the emotions: A history of changing outlooks. Annual review of psychology, 44(1), 1-22.

Krohne, H. W. (2002). Stress and coping theories. International Encyclopedia of the Social Behavioral Sciences, 22, 15163-15170.

Kumar, S., \& Bhukar, J. P. (2013). Stress level and coping strategies of college students. Journal of Physical Education and Sport Management, 4(1), 5-11.

Mahapatra, A., \& Sharma, P. (2020). Education in times of COVID-19 pandemic: Academic stress and its psychosocial impact on children and adolescents in India. International Journal of Social Psychiatry, 0020764020961801.

Mason, H. D. (2017). Meaning as a coping resource: Experiences of nursing students. Journal of Psychology in Africa, 27(1), 74-79.

Mazo, G. N. (2015). Causes, effects of stress, and the coping mechanism of the Bachelor of Science in Information Technology students in a Philippine University. Journal of Education and Learning, 9(1), 71-78. 
Mcleod, S. (2019, May 20). P-values and statistical significance. Simplypsychology.org. Simply Psychology. Retrieved May 3, 2021, from https://www.simplypsychology.org/p-value.html

Pandey, S. (2017). Emotional stability: a study on ad. Research Journal of Management, 6(9), 17-20.

Pascoe, M. C., Hetrick, S. E., \& Parker, A. G. (2020). The impact of stress on students in secondary school and higher education. International Journal of Adolescence and Youth, 25(1), 104-112.

Rha, I., \& Sung, E. (2005). Emotional expression factors and the dimensions of interactive messages in online learning community. Journal of Lifelong Learning Society, 1(1), 49-70.

Scott, W.A. (1968). Conceptions of Normality. In E.E. Borgatta and W.S. Lambert (Eds.). Handwork of Personality Theory and Research. Chicago: Rand Mc Nally.

Seňová, A., \& Antošová, M. (2014). Work stress as a worldwide problem in present time. Procedia-Social and Behavioral Sciences, 109, 312-316.

Serebryakova, T. Y. A., Morozova, L. B., Kochneva, E. M., Zharova, D. V., Kostyleva, E. A.,

\& Kolarkova, O. G. (2016). Emotional Stability as a Condition of Students' Adaptation to Studying in a Higher Educational Institution. International Journal of Environmental and Science Education, 11(15), 7486-7494.

Smitson, W.S. (1974). The meaning of emotional maturity. MH, winter 58, 9-11.

Son, C., Hegde, S., Smith, A., Wang, X., \& Sasangohar, F. (2020). Effects of COVID-19 on college students' mental health in the United States: Interview survey study. Journal of medical internet research, 22(9), e21279.

Sorono-Gagani, F., \& Bonotan, A.M. (2017, Jan). Developing and validating an instrument to evaluate a mathletes training program. Asia Pacific Journal of Education, Arts \& Sciences, 4(1), 1-9.

Sternberg, E. M. (2009). The balance within: The science connecting health and emotions. New York: W.H. Freeman.

Stress management - Care at Mayo Clinic - Mayo Clinic. (2019). Mayoclinic.org. Retrieved November 12, 2019, from https://www.mayoclinic.org/tests-procedures/stressmanagement/care-at-mayo-clinic/pcc-20384900

Sullivan, M., III. (2017). Statistics: Informed Decisions Using Data. Pearson. https://www.pearson.com/us/higher-education/product/Sullivan-Statistics-InformedDecisions-Using-Data-5th-Edition/9780134133539.html

Tuncay, N., Müdüroglu, R., \& Bulut, A. (2020). Educational Stress, Social Stress and Gender Differences among University Students. Online Submission, 10(2), 37-46.

Vinney, Cynthia. (2020, August 28). Freud: Id, Ego, and Superego Explained. Retrieved from https://www.thoughtco.com/id-ego-and-superego-4582342.

Zapata, A.D. (2015). The emotional stability and emotional maturity of fourth-year teacher education students of the Bulacan state university. The Journal of social sciences and humanities, 1 . 